\title{
Fry Survival Rate as a Predictive Marker of Optimal Production of Silver Carp (Hypophthalmichthys molitrix, Valenciennes 1844): A Biostatistical Study in Deroua Fish Farm, Morocco
}

\author{
Fatima-Zahra Majdoubi $^{1,2,3} \cdot$ Anouar Ouizgane $^{1} \cdot$ Sana Farid $^{1} \cdot$ Laura Mossetti $^{3}$. \\ Mohammed Droussi $^{4} \cdot$ Giulia Guerriero $^{3} \cdot$ Mustapha Hasnaoui $^{1}$
}

Received: 4 June 2021/Revised: 24 July 2021 / Accepted: 26 July 2021 / Published online: 12 August 2021

(C) The Author(s) 2021

\begin{abstract}
Several indicators show that the world population is rapidly increasing with prospects of reaching close to 10 billion people in 2050 . Optimal production of fish is a tentative goal to ensure human feeding and resources sustainability. The present study was performed on eggs of the silver carp, collected during the breeding season of consecutive years with different environmental temperature profiles at the Deroua Fisheries Station to evaluate the seasonal and inter-seasonal changes of eggs quality in order to promote a predictive marker for optimal production of silver carp. The viability of the obtained eggs was detected using ANOVA followed by the Tukey test to analyze fertilization rate, embryos survival rate, and fry survival rate. Data analysis showed no significant difference in the fertilization and survival rate of the embryos during the two breeding seasons, and therefore these can not be used as an adequate criterion to predict the viability
\end{abstract}

Giulia Guerriero, Mustapha Hasnaoui has equally contributed to this work.

\footnotetext{
Fatima-Zahra Majdoubi

f.zmajdoubi@gmail.com

Giulia Guerriero

giulia.guerriero@unina.it

$\bowtie$ Mustapha Hasnaoui

m.hasnaoui@usms.ma

1 Environmental Engineering Team, Faculty of Sciences and Techniques BO. 523, University of Sultan Moulay Slimane, Beni Mellal, Morocco

2 Deroua Fish Farm, Fkih Ben Saleh, Morocco

3 EClab, Department of Biology, University of Naples "Federico II", Naples, Italy

4 International aquaculture consultant, Beni Mellal, Morocco
}

of the fry of silver carp. Although the survival rate of the fry did not change during the first season, it changed significantly during the second when there was an increase in the environmental temperature. This factor could be responsible for the disturbance of the females' oogenesis and consequently the degradation of the eggs' quality. The results showed that the fry survival rate could be used as a parameter to predict the yield of silver carp production rather than the success of fertilization and the survival of embryos. This paper discusses the importance and scope of this approach.

Keywords Aquaculture - Statistics - Embryos ·

Fertilization · Fry · Hypophthalmichthys molitrix · Viability

\section{Introduction}

The world population is rapidly increasing, with prospects of reaching close to 10 billion people in 2050 (UN 2017). Along with other demographic changes recent reports also project that aquaculture will increase at a rate of $4.3 \%$ per year until 2022 and will keep growing over the period to 2030 albeit at a lower rate of $2 \%$ per year (FAO 2016; OECD 2016). Fish, as known, is an exceptional food recognized by its value in macronutrients like healthy fats and proteins, providing energy and structural molecules. Vitamins and minerals are micronutrients with a significant role in development and health. Fish are rich in essential minerals such as iodine, selenium, zinc, iron, calcium, phosphorus, potassium, and vitamins such as $\mathrm{A}, \mathrm{B}$, and $\mathrm{D}$.

Moreover, freshwater fish production represents over 62.5 percent of the world's farmed food fish production (FAO 2020). Silver carp, Hypophthalmichthys molitrix, has been an essential source for securing food supply and the 
development of commercial fishing in Morocco and locally, in Deroua fish farm at Fkih Ben Saleh, since 1981.

Silver carp is one of the most cultured fish species globally due to its high growth and feeding efficiency. It provides high-quality proteins at a lower cost than other farmed fish species. Farmed carp meat contains about $78.33 \pm 0.06$ of moisture, $15.80 \pm 0.12$ of protein, and $2.12 \pm 0.48$ of lipids. Also, the nutritional composition may differ between farmed and wild fish (Ashraf et al. 2011). Also, the amino acids are higher in farmed silver carp, which can be due to the cultivated species' diet. Kindong et al. (2017) report that silver carp tissues contain nine indispensable essential amino acids beneficial for human health (Threonine, Iso-Leucine, Tryptophan, Lysine, Phenylalanine, Valine, Histidine, Methionine, and Leucine).

Besides, silver carp meat and eggs present an important source of essential fatty acids for human nutrition containing high proportions of palmitic acid, oleic acid, alphalinolenic, docosahexaenoic acid (DHA) and eicosapentanoic acid (EPA) (Kindong et al. 2017; Majdoubi et al. 2020). Consequently, silver carp offers a potential source of the $n-3$ fatty acids necessary for human health, early development, and the prevention of some diseases (Taşbozan and Gökçe 2017). In the food processing industry, we can find several kinds of food products fabricated from silver carp meat, such as fermented sausages (Xu et al. 2010). Researchers, also, extracted a hydrolysate protein from silver carp characterized by an antioxidant power to inhibit lipid peroxidation. This led to undesirable flavors and potentially toxic reaction products in food (Dong et al. 2008).

Typically, the greater knowledge of the factors influencing the production and quality of fish eggs and the survival of the fry contributes to improving the yield of fish production on farms and secures a sustainable food source for the growing population. Hence, numerous studies have been conducted to decode the determinants of the quality of fish eggs and their relationship with the survival and growth performance of the larvae. Nutrition, endocrine status, physiological antioxidative defense, temperature, photoperiod, salinity, and pollutants influence the development of aquatic organisms as well as the quality of oocytes (Guerriero et al. 2002, Guerriero et al. 2004, Guerriero et al. 2005, Guerriero et al. 2009, De Maio et al. 2014, Guerriero et al. 2018a, 2018b, 2018c, Parisi and Guerriero 2019, Abdel-Gawad et al. 2020, Gentilucci et al. 2021, Ariano et al. 2021). Intrinsic factors such as maternal age and genetics also directly impact egg quality (Carillo et al. 2000; Venturelli et al. 2010; Macchi et al. 2013). For many farmed fish species, identifying these factors and the degree of their impact will serve as tools for fish farmers to produce a large number of viable eggs with high survival and optimal fry growth (Lubzens et al. 2017). Morphological, physiological, biochemical, and statistical biomarkers of egg quality (Berkeley et al. 2004; Guerriero et al. 2004, Guerriero 2007, Treasurer and Ford 2010, Majdoubi et al. 2017, Buhjel 2011, Majdoubi et al. 2020) can provide scientific support to identify the factors influencing the success of reproduction. In particular, the success of fertilization or "fertilization rate" is widely used to determine the quality of eggs in the early stages of an embryo's development (Papadaki et al. 2008, Bobe and Labbé 2009). The evaluation of an embryo's development during incubation and survival of embryos is also used to assess the quality of eggs in commercial hatcheries (Kjorsvik 2003, Mylonas et al. 2003). Knowledge of the variability of egg quality during the breeding season of fish is essential to improve productivity in farms. Researchers rely on statistics to design experiments, survey research, analyze data, and present findings accurately, and this approach seems not applied to these matters on silver carp. Hence, determining seasonal and inter-annual changes in egg quality is an effective tool for optimizing egg collection and larval production (Mylonas et al. 2004, Castet 2011, Majdoubi et al. 2020).

This study presents an effective method for highlighting the viability changes applied in silver carp eggs. Our goal is to increase the productivity of the carp culture and ensure a sustainable food resource without additional costs based on the biostatistical management of breeding operations during the breeding season. For this reason, we used statistical analyses of data of fertilization rate, the survival rate of embryos, and the survival rate of fry to predict the reproductive success of this species. As a case study, we chose broodfish bred in Deroua fishing in Morocco.

\section{Materials and Methods}

\section{Study Site and Broodfish}

Artificial breeding experiments were performed using the broodfish reared at Deroua fisheries. Breeders were raised in earthen ponds and fed on phytoplankton (Diatomophyceae and Chlorococcales) naturally available in these ponds (Farid et al. 2017). Adult fish were caught during five different periods $(\mathrm{P})$ of the breeding season of 2018 and 2019 (see in detail in Table 1). The temperature of the fishing station of Deroua recorded in 2019 was higher than that of 2018, whereas the optimal temperature for silver carp reproduction is between 22 and $28{ }^{\circ} \mathrm{C}$ (Billard 1979). Breeders were transported to the hatchery and put into acclimatization tanks where the water temperature was maintained at $24{ }^{\circ} \mathrm{C}$. Every breeder was weighted and marked by a colored net in its dorsal fin. To perform the 
Table 1 Temperature $\left(\mathrm{T}^{\circ} \mathrm{C}\right)$ recorded during different operative period (OP) of ova extraction of silver carp at Deroua Farm, Morocco in year 2018 and 2019

\begin{tabular}{lll}
\hline Periods & $\mathrm{T}{ }^{\circ} \mathrm{C} 2018$ & $\mathrm{~T}{ }^{\circ} \mathrm{C} 2019$ \\
\hline OP1: 1 April-15 April & 19 & 26 \\
OP2: 16 April-30 April & 24.5 & 26 \\
OP3: 1 May-15 May & 18 & 27 \\
OP4: 16 May-31 May & 31.6 & n.d \\
OP5: 16 June-30 June & 34 & n.d \\
\hline
\end{tabular}

n.d.: not detected

hormonal injection with carp pituitary extract (C.P.E: carp pituitary extract, ARGENT aquaculture, Redmond, WA 98,052 USA), every breeder was weighted and marked by a colored net in its dorsal fin. To induce ovulation, females received the first injection, immediately after acclimatization $(3 \mathrm{~h})$, at a rate of $0.3 \mathrm{mg} / \mathrm{kg}$ of their weight. After $12 \mathrm{~h}$, females received a second injection at a rate of $3 \mathrm{mg} /$ $\mathrm{kg}$ of their weight. To induce spermiation, males received a single injection of $3 \mathrm{mg} / \mathrm{kg}$ of their weight. Males' injection and females' first injection were carried out simultaneously following the Horvath method (2015). They were anesthetized by immersion for $2 \mathrm{~min}$ at $50 \mathrm{mg} / \mathrm{L}$ in a natural compound to avoid breeders' stress of manipulation, which might cause failure in ovulation (Masoumeh and Masoumeh 2018).

\section{Fertilization and Hatching}

Gametes were stripped by gentle pressure on the posterior part of the belly of each breeder. The fertilization process was carried out in dry conditions. For each female, the extracted ova were recovered in a container and immediately fertilized by the milt of three males at least.

After the swelling process of the fertilized eggs, $1 \mathrm{~L}$ of dry eggs would become 6-9 L of swollen eggs, as reported in Horvath (2015). After the hydration of the eggs, every single batch was incubated in conical hatching jars of $40 \mathrm{~L}$. These incubators were powered by a water flow in which the temperature ranged between $23{ }^{\circ} \mathrm{C}$ and $24{ }^{\circ} \mathrm{C}$.

\section{Determination of Eggs Quality}

In 2018, egg development was assessed during the breeding of 49 females whose weight varied from $1.7 \mathrm{~kg}$ to $6.3 \mathrm{~kg}$. The following year, the experiment of artificial breeding was carried out on 34 females. Their weight ranged from $1.8 \mathrm{~kg}$ to $5.7 \mathrm{~kg}$.

The quality of stripped eggs was evaluated by determining three viability rates (fertilization, embryos survival rate, and fry survival rate). To evaluate the changes of the eggs viability during the breeding season we considered 15 days as period. Every period contains a number of artificial breeding operations (OP).

- At $12 \mathrm{~h}$ after incubation, the fertilization rate was estimated as the ratio of the number of fertilized eggs and the total number of eggs in the sample.

- At $20 \mathrm{~h}$ after fertilization, the survival rate of embryos was detected as equal to the number of viable embryos / total number of embryos in the sample $* 100$.

- The survival rate of fry was determined at $30 \mathrm{~h}$ after fertilization (Fig. 1). Survival rate was of Fry = (number of live fry / total number of fry in the sample) $* 100$.

\section{Biostatistics}

Data were analyzed using the one-way analysis of variance ANOVA, followed by the Tukay's test to evaluate the eggs' viability changes during the breeding season. Then, Pearson's test was carried out to determine the correlation between the three viability rates (Fertilization rate, FR; embryos survival rate, ESR and fry survival rate, FSR) and spawning time. SPSS version 23 software and Excel 2010 for windows were adopted to perform the statistical analysis. All represented data were expressed as mean \pm SEM. $P<0.05$ was considered significant.

\section{Results}

During the breeding season of 2018, the fertilization rate was higher in the middle of the season with an overall average of $67.96 \%$ (OP2) and $66.5 \%$ (OP3). The lowest values were recorded at the end of the season with an overall average of $61.75 \%$ and $61.80 \%$ for OP4 and OP5, respectively. Further, the embryos survival rate was lower at OP3 (46.10\%) and OP4 (48\%). While, the highest embryos survival rate was obtained at OP5 (72.4\%), which was the end of the reproductive season. Moreover, at the beginning of the reproductive season, the embryos survival was positive with an overall average of $66.93 \%$ for OP1 and $57.59 \%$ for OP2.

In 2019, the breeding operations were performed only during the three first 15 days of the reproductive season as reported in Table 2. In general, the fertilization rates were satisfying during all the performed breeding operations. It increased from $50.66 \%$ in OP1 to reach $55.27 \%$ in OP3. Concerning the survival of embryos, it was higher at OP2 $(54.07 \%)$ followed by OP1 $(50.50 \%)$. However, it depleted at OP3 to reach an overall average of $40.62 \%$.

The assessment of fry survival during the reproductive season of 2018 revealed that seed production was optimal, 
Fig. 1 Photographs showing dead and viable larvae (a) and viable larvae (b). Viable larvae, indicated with an arrow, have a translucent yolk sac
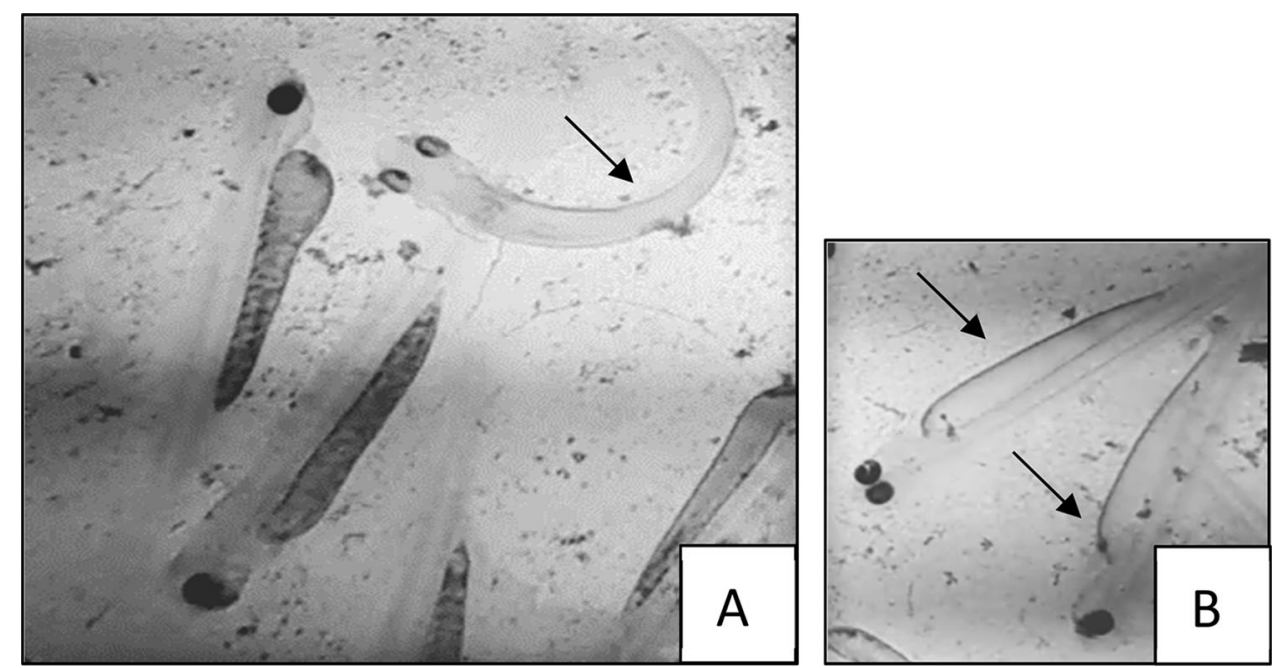

\begin{tabular}{llllllll}
\hline Periods & \multicolumn{2}{l}{ Season-2018 } & & \multicolumn{3}{l}{ Season-2019 } \\
\cline { 2 - 3 } & FR $(\%)$ & ESR $(\%)$ & SRF $(\%)$ & & FR $(\%)$ & ESR (\%) & SRF (\%) \\
\hline OP1: 1 April-15 April & 63.31 & 66.93 & 98.84 & & 50.66 & 50.50 & 81.77 \\
OP2: 16 April-30 April & 67.96 & 57.59 & 73.09 & & 51.20 & 54.07 & 70.19 \\
OP3: 1 May-15 May & 65.50 & 46.10 & 79.60 & & 55.27 & 40.62 & 43.29 \\
OP4: 16 May-31 May & 61.75 & 48,00 & 100.00 & & n.d & n.d & n.d \\
OP5: 16 June-30 June & 61.80 & 72.40 & 74.67 & & n.d & n.d & n.d \\
\hline
\end{tabular}

n.d.: not detected

Table 2 Viability rates (FR, Fertilization Rate; ESR, Embryos Survival Rate, FSR, Fry Survival Rate) of silver carp ova extracted within the same reproductive season period $(\mathrm{OP})$ and the lowest average was $73.09 \%$ (OP2) while the highest value was $100 \%$ (OP4). On the other hand, the fry survival decreased throughout the reproductive season of 2019. It declined from $81.77 \%$ (OP1) to $43.29 \%$ (OP3) (Table 2).

Based on Pearson's test, fertilization rate (FR) and survival rate of embryos (ESR) correlated significantly $(r=0.519)$ in 2018. Similarly, the correlation was positive between the Fertilization rate (FR) and the survival rate of fry (FSR) $(r=0.421)$, while the association between the embryos survival rate (ESR) and the fry survival rate (FSR) was positive but non-significant $(r=0.289)$. Unexpectedly, the correlation test performed on the data of the second reproductive season (2019) showed no strong correlation between fertilization rate (FR) and the embryos survival rate $\operatorname{ESR}(r=0.136)$.

The same result was obtained for the correlation between the fertilization rate and the fry survival rate ( $r=-0.016)$. Further, the association between the embryos' survival and the fry survival was significant and positive $(r=0.521)$. Moreover, the asymmetry of the median in the boxplots (Fig. 2) revealed the heterogeneity within individuals of the same group. This finding sheds light on the intraspecific effect on the variability of FR and
ESR. Concerning the survival of embryos, the barplots (Fig. 2) showed that during the season 2018, lowest value was obtained in OP4 while the highest value was in OP5. In season 2019, the lowest value was also obtained at OP4 and the highest value belong to OP5. Further, these barplots are overlapped which confirms the absence of significant difference of embryos survival rate.

Besides, the comparison between the two successive seasons showed that in the first season (2018), the overall viability rates (FR and ESR) were higher than those achieved in the second season (2019) (Fig. 3).

The overall fertilization rate decreased from $64.06 \%$ in 2018 to $52.38 \%$ in 2019 . Embryos' survival was $58.10 \%$ in 2018 and declined to reach $48.4 \%$ in 2019 . Finally, the fry survival rate reached an overall rate of $85.24 \%$ in 2018 , while it dropped to $65.08 \%$ in 2019 .

\section{Discussion}

The optimal production of fish is a tentative goal to ensure human feeding and resources sustainability. The viability of the obtained eggs was detected using a biostatistical approach by assessing fertilization rate, embryos survival, 

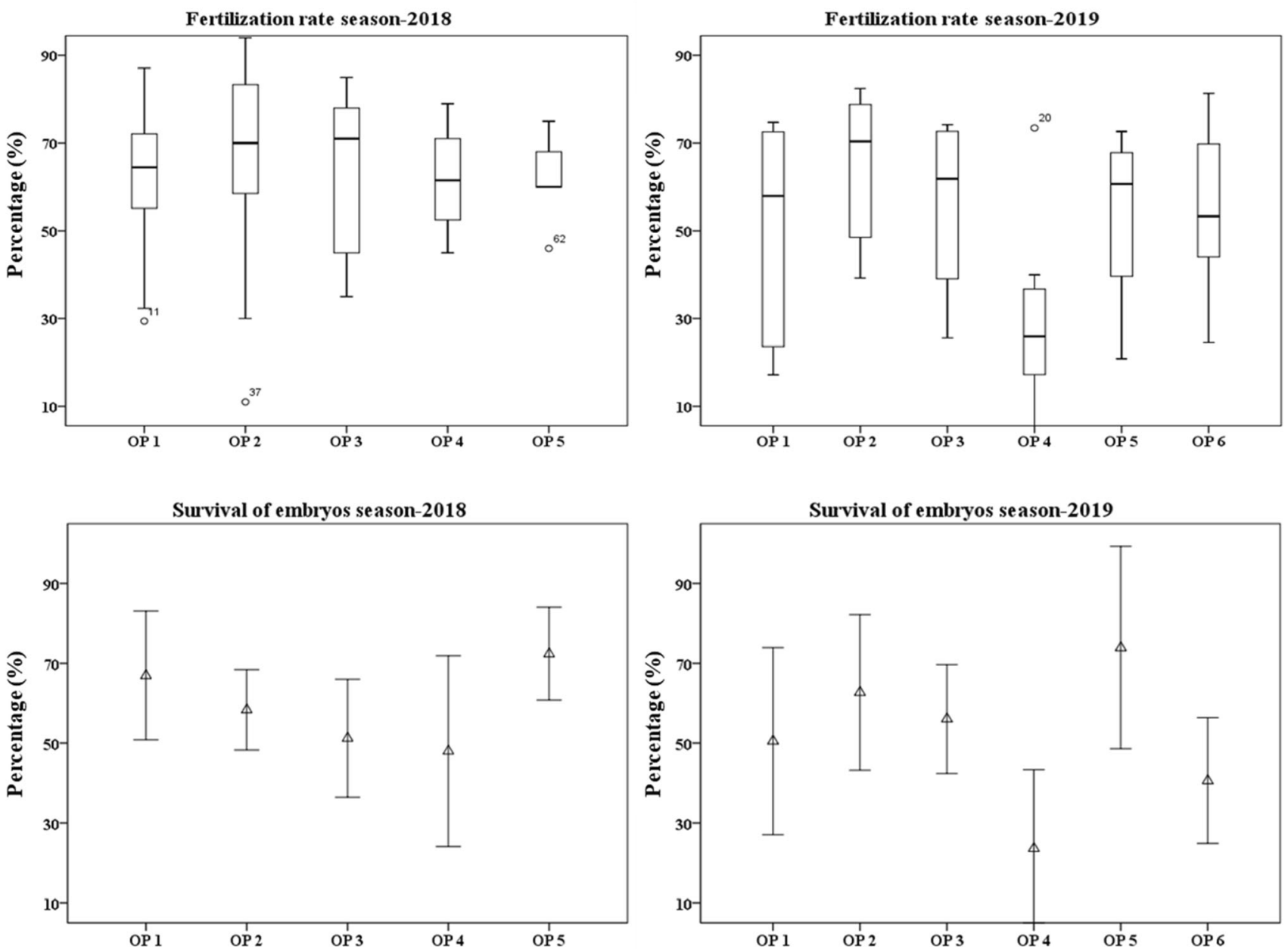

Fig. 2 Boxplots presenting the variation of fertilization rate and survival of embryos for all the performed breeding operations during the reproductive season-2018 and season-2019 of silver carp. Abbrev: OP, Operative Period of artificial reproduction performed. Number $11,37,62$ related to fertilization rate season-2018 refers to females'

and fry survival rates. This pioneering approach has been performed in Hypophthalmichthys molitrix, one of the representative fish sources for guaranteeing food supply and the development of commercial fishing in Morocco.

One-way ANOVA showed that no significant difference between the means of the fertilization rate and the embryos' survival rate $(p>0.05)$ during the two annual reproductive seasons. In addition, there was no temporal effect on fertilization success and the normal development of the embryos. So, they cannot serve to determine the changes of the females' reproductive outcome in silver carp during the same reproductive season. However, these viability rates are valuable tools that give predictive information about the success and the yield of the performed breeding operation. Identically, Skaalsvik et al. (2015) found that in Atlantic halibut (Hippoglossus hippoglossus L.), the fertilization rate and survival rate of

number which gave the lowest FR than females manipulated in OP1, OP2, and OP5; Number 20 related to fertilization rate season-2019 refers to females's number which gave the highest FR than femalecontrolled in OP4. Each value represents a mean \pm SEM

larvae did not change throughout the spawning season. This invariability was explained by the absence of parental effect on the quality of the eggs during the experiment. The same study highlighted that the fertilization rate remained a predictive tool for the hatching success only for batches with low fertilization success. Similar results were found for the Ballan wrasse (Labrus bergylta) in which the fertilization rate remained high during its reproductive season (up to 87.5\%) (Grant et al. 2016). Other studies revealed that fertilization rate represented a significant parameter to determine egg quality in many fish species (Brown et al. 2006; Policar et al. 2010; Jerez et al. 2012). In gilthead seabream (Sparus aurata), fertilization success changed during the spawning season. It was demonstrated that higher rates were obtained in early and mid-season, then it depleted at the end of the reproductive season (Jerez et al. 2012). The assessment of the reproductive potential of 
Fig. 3 Interannual variation of silver carp viability rates (fertilization rate, survival of embryos and survival) between the two successive breeding seasons (season-2018 and season-2019). Each bar represents a mean \pm SEM

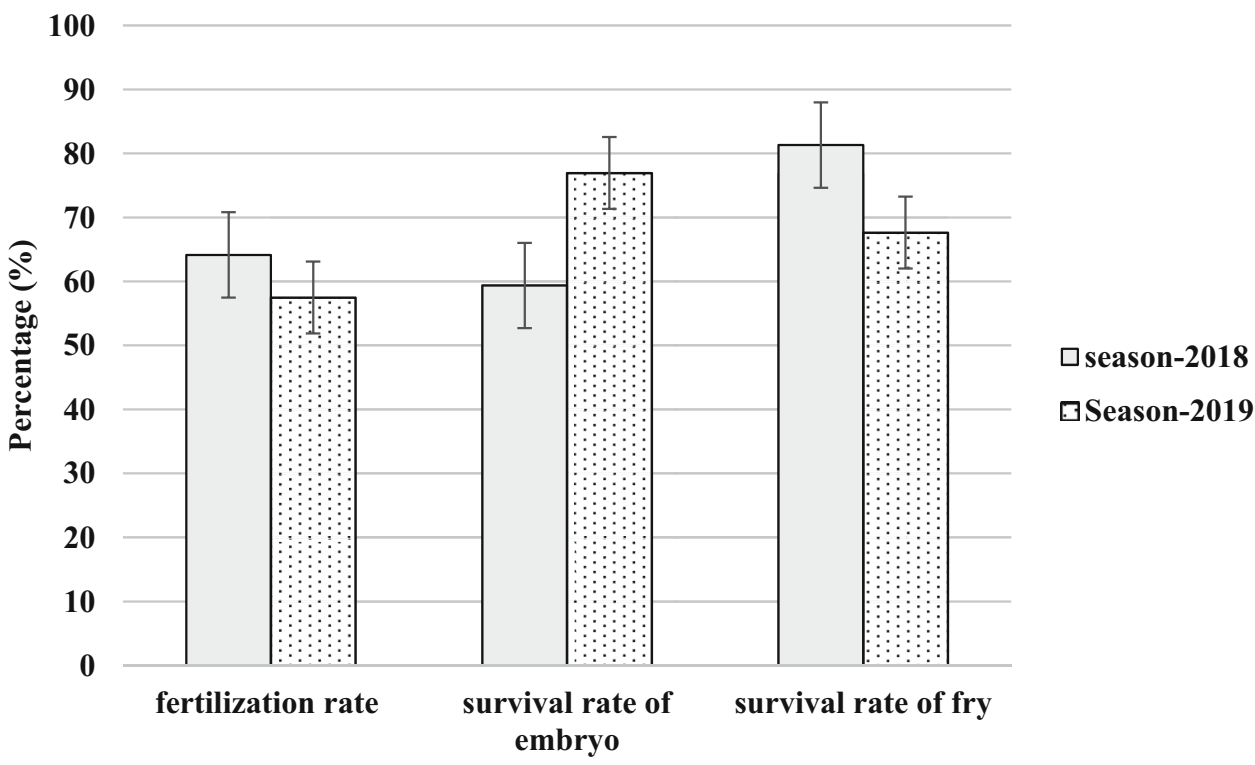

common barbel (Barbus barbus) revealed that the lowest fertilization rates were obtained at the beginning and the end of the reproductive season (Policar et al. 2010).

Besides, the statistical treatment of data related to the survival of fry showed that the fry survival rate did not change during the first season. Nevertheless, this rate was significantly variable throughout the second one. Low fry mortalities were obtained at the beginning of the season (1-15 April and 16-30 April), while at the end, the mortalities were higher. Same reproductive kinetics was observed in Dentex dentex (Giménez et al. 2006), Merlangius merlangus L (Treasurer and Ford 2010) and Perca fluviatilis (Castets 2011). For the European perch (Perca fluviatilis) the viability of the ova decreased during the breeding season. Eggs of superior quality were those stripped at the beginning of this period. In comparison, those obtained at the end of the same season were considered of inferior quality (Castets 2011). Treasurer and Ford (2010) found that the quality of the eggs of Merlangius merlangus $L$ correlated unfavorably with time. The fertilization rate, egg diameter, and dry and wet weight dropped significantly with the progress of the spawning season.

During the same breeding season, the changes in fertilization success and embryos survival could be explained by the dominance of intraspecific factors. Figure 2 highlights the heterogeneity between females of the same group. This can be supported by other studies which proved the existence of a strong effect of parental fitness on the survival of eggs and embryos (Johnson et al. 2012). However, in our study, the age and weight of the female did not affect egg viability, which means that other maternal factors affect egg quality. For instance, it was proved in numerous studies that the maternal nutritional status had an impact on eggs and fry growth and survival (Izquierdo et al. 2001; Mazorra et al. 2003; Watanabe and Vassallo-Agius 2003; Sink and Lochmann 2008).

The correlation between the chosen viability rates revealed a significant correlation between fertilization rate and survival rate of embryos. However, there is no significant correlation between the survival of fry and the fertilization rate or survival rate of embryos. Consequently, these findings highlight that fertilization success or embryos survival cannot be used as a predictive criterion to predict fry viability in silver carp. Contrariwise to other fish species, fertilization success can predict fry survival (Mylonas et al. 2004).

During this study, the temperature profile was distinct between the two years. During the second year, an increase in temperature could be responsible for the perturbation of oogenesis of females and, consequently, a degradation of egg quality (see Parisi and Guerriero 2019 for review in fish eggs). Moreover, these fluctuations in temperature caused disquiet in fish's reproductive behavior, which was represented by low fecundity and failure of ovulation for a considerable number of females (unpublished results). In addition, deformities of embryos and fry were primarily observed during the second season (data not shown). Brown et al. (2006) showed that for Atlantic halibut (Hippoglossus hippoglossus L.), elevated temperatures during the vitellogenesis caused a decrease in quantity and quality of eggs. Consequently, the inferior quality of eggs obtained during the second season might be caused by the overripening or the inhibition of the spawning stimulated by the sudden increase in temperature.

The present research on the variability of eggs quality of silver carp during its reproductive season was performed to determine a more effective way for female manipulation 
and conditioning to obtain an optimal reproductive outcome during the induced breeding operations. Statistically, the present study demonstrated that silver carp reproductive success was related to several factors (e.g., environmental, maternal effects). It revealed that fry survival rate could be used as a parameter to predict the yield of silver carp production instead of the fertilization success and survival of embryos. Our approach contributes to the value of statistics for aquaculture as well by providing userfriendly coverage of statistical principles and practical methods to fill that gap.

Acknowledgements This work was done in the framework of the Memorandum of Understanding between the University of Sultan Moulay Slimane, Beni Mellal (Morocco), and Federico II University, Naples (Italy). The authors acknowledge Ms. Dhouha Mabrouk for careful proofreading and editing of the manuscript.

Funding Open access funding provided by Università degli Studi di Napoli Federico II within the CRUI-CARE Agreement.Open Access This article is licensed under a Creative Commons Attribution 4.0 International License, which permits use, sharing, adaptation, distribution and reproduction in any medium or format, as long as you give appropriate credit to the original author(s) and the source, provide a link to the Creative Commons licence, and indicate if changes were made. The images or other third party material in this article are included in the article's Creative Commons licence, unless indicated otherwise in a credit line to the material. If material is not included in the article's Creative Commons licence and your intended use is not permitted by statutory regulation or exceeds the permitted use, you will need to obtain permission directly from the copyright holder. To view a copy of this licence, visit http://creativecommons.org/licenses/by/4.0/.

\section{References}

Abdel-Gawad, FKh., W.K.B. Khalil, S.M. Bassem, V. Kumar, C. Parisi, S. Inglese, T.A. Temraz, H.F. Nassar, and G. Guerriero. 2020. The duckweed Lemna minor modulates heavy metalinduced oxidative stress in the Nile tilapia Oreochromis niloticus. Water 12 (11): 2983.

Ariano, A., N. Musco, L. Severino, A. De Maio, A. Tramice, G. Tommonaro, S. Damiano, A. Genovese, O.S. Olanrewaju, F. Bovera, and G. Guerriero. 2021. Chemistry of tropical eucheumatoids: Potential for food and feed applications. Biomolecules 11: 804.

Ashraf, M., Zafar, A., Rauf, A., Mehboob, S., and Qureshi, N. A. 2011. Nutritional values of wild and cultivated silver carp (Hypophthalmichthys molitrix) and grass carp (Ctenopharyngodon idella). International Journal of Agriculture and Biology 13(2).

Berkeley, S.A., C. Chapman, and S.M. Sogard. 2004. Maternal age as a determinant of larval growth and survival in a marine fish, Sebastes melanops. Ecology 85: 1258-1264.
Bhujel, R.C. 2011. Statistics for aquaculture, 1-240. Incorporated, John edition: Wiley \& Sons.

Billard, R. 1979. La gamétogenèse, le cycle sexuel et le contrôle de la reproduction chez les poissons téléostéens. Bulletin Français De Pisciculture 273: 117-136.

Bobe, J., and C. Labbé. 2009. Egg and sperm quality in fish. General and Comparative Endocrinology 2010 (165): 535-548.

Brown, N.P., R.J. Shields, and N.R. Bromage. 2006. The influence of water temperature on spawning patterns and egg quality in the Atlantic halibut (Hippoglossus hippoglossus L.). Aquaculture 261 (3): 993-1002.

Carrillo, M., Zanuy, S., Oyen, F., Cerdá, J., Navas, J. M., and Ramos, J. 2000. Some criteria of the quality of the progeny as indicators of physiological broodstock fitness. Recent advances in Mediterranean aquaculture finfish species diversification p.61-73.

Castets, M. D. 2011. Fonction de reproduction et régulation de la qualité chez la perche commune (Perca fluviatilis). Institut National Polytechnique De Lorraine (INPL), École Nationale Supérieure d'Agronomie et des Industries Agroalimentaires.

De Maio, A., S. Trocchia, and G. Guerriero. 2014. The amphibian Pelophylax bergeri (Günther, 1986) testis poly(ADP-ribose) polymerases: Relationship to endocrine disruptors during spermatogenesis. The Italian of Zoology 81: 256-263.

Dong, S., M. Zeng, D. Wang, Z. Liu, Y. Zhao, and H. Yang. 2008. Antioxidant and biochemical properties of protein hydrolysates prepared from Silver carp (Hypophthalmichthys molitrix). Food Chemistry 107 (4): 1485-1493.

Food and Agriculture Organization (FAO). 2016. The State of World Fisheries and Aquaculture (2016) Contributing to food security and nutrition for all. Rome, pp 1-3.

Food and Agriculture Organization (FAO). 2020. The State of World Fisheries and Aquaculture 2020. Sustainability in action. Rome, pp 24-26. https://doi.org/10.4060/ca9229en

Farid, S., A. Ouizgane, M. Droussi, and M. Hasnaoui. 2017. Evolution des paramètres zootechniques de la carpe argentée (Hypophthalmichthys molitrix) élevée sous climat semi-aride a la station de pisciculture Deroua, Maroc. Journal of Water and Environmental Sciences 1: 115-122.

Gentilucci, M., C. Parisi, M.R. Coppola, F.-Z. Majdoubi, M. Madonna, and G. Guerriero. 2021. Influence of mediterranean sea temperature increase on Gaeta Gulf (Tyrrhenian Sea) biodiversity. Proceedings of the Zoological Society 74: 91-103.

Giménez, G., A. Estévez, F. Lahnsteiner, B. Zecevic, J.G. Bell, R.J. Henderson, J.A. Piñera, and J.A. Sanchez-Prado. 2006. Egg quality criteria in common dentex (Dentex dentex). Aquaculture 260 (1-4): 232-243.

Grant, B., A. Davie, J.B. Taggart, S.L. Selly, N. Picchi, C. Bradley, P. Prodohl, and H. Migaud. 2016. Seasonal changes in broodstock spawning performance and egg quality in ballan wrasse (Labrus bergylta). Aquaculture 464: 505-514.

Guerriero, G. 2007. Seasonal steroids variations and maturity stages in the female chub, Leuciscus cephalus L. (Pisces, Cyprinidae). Italian Journal of Zoology 74 (4): 317-324.

Guerriero, G., A. Di Finizio, and G. Ciarcia. 2002. Stress-induced changes of plasma antioxidants in aquacultured sea bass. Dicentrarchus Labrax. Comparative Biochemistry and Physiology. Part A 132: 205-211.

Guerriero, G., R. Ferro, G.L. Russo, and G. Ciarcia. 2004. Vitamin E in early stages of sea bass (Dicentrarchus labrax) development. Comparative Biochemistry and Physiology Part a: Molecular \& Integrative Physiology 138 (4): 435-439.

Guerriero, G., R. Ferro, and G. Ciarcia. 2005. Correlation between plasma levels of sex steroids and spermatogenesis during the sexual cycle in the chub, Leuciscus cephalus L. (Pisces: Cyprinidae). Zoological Studies 44: 228-233. 
Guerriero, G., C.E. Roselli, and G. Ciarcia. 2009. The amphibian (Rana esculenta) brain progesterone receptor: Relationship to plasma steroids and vitellogenic cycle during the gonadal recovery phase. In Trends in comparative endocrinology and neurobiology, ed. H. Vaudry, et al. New York: Annals of New York Academy of Sciences.

Guerriero, G., S.M. Bassem, W.K.B. Khalil, T.A. Temraz, G. Ciarcia, and FKh. Abdel-Gawad. 2018a. Temperature changes and marine fish species (Epinephelus coioides and Sparus aurata): Role of oxidative stress biomarkers in toxicological food studies. Emirates Journal of Food and Agriculture. https://doi.org/10. 9755/ejfa.2018.v30.i3.1650.

Guerriero, G., M.V. Brundo, S. Labar, A.R. Bianchi, S. Trocchia, D. Rabbito, G. Palumbo, FKh. Abdel-Gawad, and A. de Maio. 2018b. Frog (Pelophylax bergeri, Gunther 1986) endocrine disruption assessment: Characterization and role of skin poly(ADP-ribose) polymerases. Environmental Science and Pollution Research 25: 18303-18313.

Guerriero, G., R. Di Giaimo, O. Hentati, FKh. Abdel-Gawad, S. Trocchia, D. Rabbito, and G. Ciarcia. 2018c. Reproductive expression dynamics and comparative toxicological perspective of beta estrogen receptor gene in the male wall lizard, Podarcis sicula Rafinesque, 1810 (Chordata: Reptilia). The European Zoological Journal 85: 332-342.

Horváth, L., Tamás, G., Coche, A. G., Kovacs, E., Moth-Poulsen, T., and Woynarovich, A. 2015. Training manual on the advanced fry and fingerling production of carps in ponds. In: A handout for on-farm training workshop on fish seed production of Common carp and Chinese. Therefore carps in Central and Eastern Europe, the Caucasus and Central Asia. Second revised edition. Budapest, FAO-REU. http://www.fao.org/3/a-i4317e. pdf.

Izquierdo, M.S., H. Fernandez-Palacios, and A.G.J. Tacon. 2001. Effect of broodstock nutrition on reproductive performance of fish. Aquaculture 197: 25-42.

Jerez, S., C. Rodríguez, J.R. Cejas, M.V. Martín, A. Bolaños, and A. Lorenzo. 2012. Influence of age of female gilthead seabream (Sparus aurata L.) broodstock on spawning quality throughout the reproductive season. Aquaculture 350: 54-62.

Johnson, C.L., P. Roni, and G.R. Pess. 2012. Parental effect as a primary factor limiting egg-to-fry survival of spring Chinook salmon in the Upper Yakima River Basin. Transactions of the American Fisheries Society 141: 1295-1309.

Kindong, R., N. Prithiviraj, A. Apraku, C.L. Ayisi, and X. Dai. 2017. Biochemical composition of predatory carp (Chanodichthys erythropterus) from Lake Dianshan, Shanghai, China. Egyptian Journal of Basic and Applied Sciences 4 (4): 297-302.

Kjørsvik, E., K. Hoehne-Reitan, and K.I. Reitan. 2003. Egg and larval quality criteria as predictive measures for juvenile production in turbot (Scophthalmus maximus L.). Aquaculture 227: 9-20.

Lubzens, E., J. Bobe, G. Young, and C.V. Sullivan. 2017. Maternal investment in fish oocytes and eggs: The molecular cargo and its contributions to fertility and early development. Aquaculture 472: 107-143.

Macchi, G.J., E. Leonarduzzi, M.V. Diaz, M. Renzi, and K.A. Rodrigues. 2013. Maternal effects on the fecundity and egg quality of the Patagonian stock of the Argentine Hake (Merluccius hubbsi). NOAA's National Marine Fisheries Service. Fishery Bulletin 111: 325-336.

Majdoubi, F.Z., A. Ouizgane, M. Droussi, and M. Hasnaoui. 2017. Impact du phénomène du vieillissement in vivo des ovules de la carpe argentée (Hypophthalmichthys molitrix) sur la production des semences à la station de pisciculture de Deroua (province Fkih Ben Saleh, Maroc). Journal of Water and Environmental Sciences Special Issue COP 22 (1): 127-131.
Majdoubi, F.Z., R. Benhima, A. Ouizgane, G. Guerriero, and M. Hasnaoui. 2020. Ova fatty acids composition and spawning performances of silver carp, Hypophthalmichthys molitrix (Morocco). Turkish Journal of Fisheries and Aquatic Sciences 20 (12): 879-888. https://doi.org/10.4194/1303-2712-v20_12_04

Masoumeh, E., and B. Masoumeh. 2018. Effects of four anesthetics, clove extract, thyme extract, lidocaine, and sodium bicarbonate on the blood parameters and cortisol amount in grass carp (Ctenopharyngodon Idella). Journal of Marine Biology and Aquaculture 4 (1): 1-4.

Mazorra, C., M. Bruce, J. Bell, A. Davie, E. Alorend, N. Jordan, J. Rees, N. Papanikos, M. Porter, and N. Bromage. 2003. Dietary lipid enhancement of broodstock reproductive performance and egg and larval quality in Atlantic halibut (Hippoglossus hippoglossus). Aquaculture 227: 21.

Mylonas, C.C., I. Sigelaki, P. Divanach, E. Mananõs, M. Carrillo, and A. Afonso-Polyviou. 2003. Multiple spawning and egg quality of individual European sea bass (Dicentrarchus labrax) females after repeated injections of GnRHa. Aquaculture 221 (1-4): $605-620$

Mylonas, C.C., M. Papadaki, M. Pavlidis, and P. Divanach. 2004. Evaluation of egg production and quality in the Mediterranean red porgy (Pagrus pagrus) during two consecutive spawning seasons. Aquaculture 232 (1-4): 637-649.

Organisation for Economic Co-operation and Development (OECD). 2016. The Ocean Economy in 2030. Paris: OECD Publishing, pp 192-194. https://doi.org/10.1787/9789264251724-en

Papadaki, M., M. Papadopoulou, I. Siggelaki, and C.C. Mylonas. 2008. Egg and sperm production and quality of sharpsnout sea bream (Diplodus puntazzo) in captivity. Aquaculture 276 (1-4): 187-197.

Parisi, C., and G. Guerriero. 2019. Antioxidative defense and fertility rate in the assessment of reprotoxicity risk posed by global warming. Antioxidants 8 (12): 622.

Policar, T., P. Podhorec, V. Stejskal, J. Hamackova, and S.M.H. Alavi. 2010. Fertilization and hatching rates and larval performance in captive common barbel (Barbus barbus L.) throughout the spawning season. Journal of Applied Ichthyology 26 (5): $812-815$.

Sink, T.D., and R.T. Lochmann. 2008. Effects of dietary lipid source and concentration on channel catfish (Ictalurus punctatus) egg biochemical composition, egg and fry production, and egg and fry quality. Aquaculture 283: 68-76.

Skaalsvik, T.H., S.L. Bolla, P.O. Thornqvist, and I. Babiak. 2015. Quantitative characteristics of atlantic halibut (Hippoglossus hippoglossus L.) egg quality throughout the reproductive season. Theriogenology 83 (1): 38-47.

Taşbozan, O., and M.A. Gökçe. 2017. Fatty Acids in Fish. Fatty Acids 1: $143-159$.

Treasurer, J., and L. Ford. 2010. Assessment of egg quality and realised fecundity of whiting Merlangius merlangus L. in captivity. Journal of Applied Ichthyology 26 (4): 554-560.

United Nations. 2017. World Population Prospects: The 2017 Revision, Key Findings and Advance Tables. Department of Economic and Social Affairs, Population Division.

Venturelli, P.A., C.A. Murphy, B.J. Shuter, T.A. Johnston, Van Coeverden, P.J. de Groot, P.T. Boag, J.M. Casselman, R. Montgomerie, M.D. Wiegand, and W.C. Leggett. 2010. Maternal influences on population dynamics: Evidence from an exploited freshwater fish. Ecology 91 (7): 2003-2012.

Watanabe, T., and R. Vassallo-Agius. 2003. Broodstock nutrition research on marine finfish in Japan. Aquaculture 227 (1-4): 35-61. https://doi.org/10.1016/S0044-8486(03)00494-0. 
Xu, Y., W. Xia, F. Yang, and X. Nie. 2010. Physical and chemical changes of silver carp sausages during fermentation with Pediococcus pentosaceus. Food Chemistry 122 (3): 633-637.
Publisher's Note Springer Nature remains neutral with regard to jurisdictional claims in published maps and institutional affiliations. 